\title{
Agrometeorological advisory services for sustainable development in Indian agriculture
}

\begin{abstract}
It has been documented with fair degree of accuracy that overall climate is changing particularly in respect of temperature over the Indian region. Besides, climatic variability leading to extreme events like drought, flood, occurrence heavy rainfall etc. is increasing during last one and half decades. Thus, both climate change and climate variability are causing concern on the biodiversity and ultimately eco-system in different parts of the country. In order to address this issue and others, India Meteorological Department/Ministry of Earth Sciences is operating an initiative under Agromet Advisory Services. The Agromet Advisory Services provide a very special kind of inputs to the farmers as advisories that can make a tremendous difference to the agriculture production by taking the advantage of benevolent weather and minimize the adverse impact of malevolent weather. This has a potential to change the face of India in terms of food security and poverty alleviation. Agro-meteorological service rendered by India Meteorological Department, Ministry of Earth Sciences is a step to contribute to weather information based crop/livestock management strategies and operations dedicated to enhancing crop production in a sustainable manner. In the present paper different activities and strategies under these services have been mentioned to present an overview of the initiative and how effectively the weather and climate information are being used to help the users and also the environment.
\end{abstract}

Keywords: agrometeorological, biodiversity, meteorological, earth sciences, agromet advisory services
Volume 2 Issue I - 2018

\section{Chattopadhyay N, Chandras S}

India Meteorological Department, India

Correspondence: Chattopadhyay N, Deputy Director General of Meteorology, India Meteorological Department, Shivajinagar, Pune, Maharashtra, India, Tel+919225569519; Email nabansu.nc@gmail.com

Received: December II, 2017 | Published: January 08, 2018

\section{Introduction}

The agriculture sector must produce more food for a growing world population, which is expected to increase from 7 billion to about 9 billion by 2050. Comprehensive planning to reduce the economic and ecological impacts of extreme events as well as adoption of technologies for improved land and water management to enhance water efficiency in agriculture are needed. Indiscriminate use of pesticides and fertilisers critically imbalances the biodiversity in the natural ecosystem. Therefore, linking of weather information with the application of agrochemical could maintain the biodiversity and ultimately ecosystem. Besides, potential approaches to success include knowledge sharing and cultivation of critical thinking, the promotion of effective tools and technologies, and proper understanding of user priorities and needs. Recognizing that solutions exist but time is short, the biodiversity/conservation/ecosystem sectors need to closely collaborate with National Meteorological \& Hydrological Services to promote more environmental friendly and sustainable development. India possess a wealth of biodiversity, have experienced severe weather variability, crop failure and recurrent famine throughout their histories. To tackle the problems that arise as a result of climate change and the resultant droughts, floods, land degradation, losses of crop and biodiversity, famine, malnutrition and poverty, there is a need for greater awareness on managing the natural resources. The country needs a new integrated approach for advancement of improved technologies and good practices to manage crops and livestock, as well as the soil, land and ecological resources of the region.

Current concerns with the sustainability of agroecosystems in different parts of the world have heightened the awareness for careful use of the natural resource base on which agriculture depends. For proper and efficient use of soils and plant/animal genetic material, knowledge of the role of climate is an essential. ${ }^{1}$ The World Food Summit Plan of Action (WFSPA), which was developed in 1996, includes several commitments to make agricultural production sustainable. Agrometeorological aspects of these three Conventions and the WFSPA were reviewed. Some of the priorities for agrometeorologists to address sustainable agriculture in the $21 \mathrm{st}$ Century were discussed. This include improvement and strengthening of agrometeorological networks, development of new sources of data for operational agrometeorology, improved understanding of natural climate variability, promotion and use of seasonal to inter-annual climate forecasts, establishment and/or strengthening of early warning and monitoring systems, promotion of geographical information systems, remote sensing applications, agro-ecological zoning for sustainable management of farming systems and forestry \& livestock. Other priorities includes use of improved methods, procedures and techniques for the dissemination of agrometeorological information, development of agrometeorological adaptation strategies to climate variability and climate change, mitigation of the effects of climate change. Also more active applications of models for phenology, yield forecasting etc., active promotion of tactical applications such as response farming at the field level and promoting a better understanding of the interactions between climate and biological diversity are needed. These present important challenges and great opportunities for agrometeorologists to play a proactive role in promoting sustainable development in the 21 st Century.

Most of the farmers in India are smallholder farmers often with limited access to technologies and resources which leaves them increasingly vulnerable to weather and climate fluctuations. Increased frequency, severity and intensity of weather and climate extremes have contributed to food deficits and failure to prevent widespread famine in many high risk areas. Although farming communities throughout the world have survived by mastering the ability to adapt 
to widely varying weather and climatic conditions, increasingly erratic climate variability and the rapid pace of other drivers of change are overwhelming indigenous knowledge and traditional coping practices. Climate services are receiving increasing attention globally. Also increases in extreme weather such as floods and drought, as a result of climate change could have a negative impact on livelihoods that depend on climate-sensitive activities such as rain-fed agriculture and livestock rearing. National Meteorological Services (NMS) has great role to play to share climate information including the products with the small farmers. NMS in many cases need to be realigned, resourced and trained as providers of services for development and as participants in the development process. Climate information should reach the last mile to create impact, enough information. There is a great need to convert the climate information into actionable information for farmers. Linking the climatic information with the available technologies and best farming practices is required. Customized, location and crop specific actionable information is the requirement of the small farmers.

\section{Weather services to agriculture}

All agrometeorological and agroclimatological information that can be directly applied to try to improve and/or protect the livelihood of farmers in agricultural production may be considered to belong to agrometeorological services. This improvement/protection applies to yield quantity, quality and income while safeguarding the agricultural resource base from degradation. ${ }^{2}$ The Agromet Advisory Services provide a very special kind of inputs to the farmers as advisories that can make a tremendous difference to the agriculture production by taking the advantage of benevolent weather and minimize the adverse impact of malevolent weather. This has a potential to change the face of any country in terms of food security and poverty alleviation. Agrometeorological services rendered by India Meteorological Department (IMD), Ministry of Earth Sciences is a step to contribute to weather information based crop/livestock management strategies and operations dedicated to enhancing crop production and food security. IMD is operating a project "Gramin Krishi Mausam Sewa" (GKMS) with an objective to serve the farming community at different parts of the country. The following are the major activities being carried out under this project minimising the threat on the biodiversity in the agricultural system in India. Figure 1 depicts overview of Agromet Advisory Services in India.

\section{Generation of weather forecast \& agromet advisory}

Based on the medium range weather forecast, AAS bulletins have been prepared for 636 districts and issued on every Tuesday and Friday. State Composite bulletins (23) and National AAS bulletins have also been issued simultaneously. Efforts are being made to prepare AAS bulletins for all the districts of the country. Efforts have also been made for preparation of accurate medium range weather forecast by value addition from Regional Meteorological Centres (RMCs)/Meteorological Centres (MCs). To help the farmers to cope with climate risks and also for effectively use seasonal to interannual climate forecasts, IMD in collaboration with Central Research Institute for Dryl and Agriculture, Hyderabad continued issuing AAS Bulletins based on Extended Range Weather Forecast and Monthly Weather Forecast during southwest monsoon 2017 to fulfil the needs of different users including planners at State and National levels and farmers.

\section{Special advisories for extreme events}

In a large country like India which is experiencing cyclone, floods, droughts, hailstorms as an extreme events every year, the weather may be nullified to a large extent by suitable adoptive measures dissemination through Agromet Advisory Services ${ }^{3-5}$ by aberrations of India Meteorological Department is doing yeomen's service by providing advance information including monitoring of the disaster events by using state of art instruments \& technology. Such type of advisories is issued in cyclone, floods and droughts so that the farmers can minimize the crop loss. Also, IMD is having different kinds of network of observatories in India to monitor and assess the weather which are Conventional Observational Network, Automatic Weather Stations (AWS), Buoy/Ship Observations, Cyclone Detection Radars, Doppler Weather Radars and Satellites observations. Another two important issues which are being dealt are extreme weather events and climate change \& variability. Around 26 Doppler weather radars were installed and also various types of satellite data is being used to provide information about extreme weather events like heavy rainfall to save the crops and also contingency planning is given to the farmers for taking appropriate crops in respect of expected climate variability during the monsoon season Synoptic Methods, Statistical Methods and Numerical Weather Prediction models developed based on these observational network can be used for generation of rainfall, temperature, thunderstorm, dust storm, clouds, cyclonic storms (their courses and stages), heavy rainfall warnings, frost warning, squall warning, heat waves, cold waves etc. Digital and image information at 10 minutes interval from Doppler weather radar is very useful in addition to many other observed data in predicting thunderstorm activity. Specialized products derived from satellites such as Normalised Difference Vegetation Index (NDVI), surface insulation, Leaf Surface Temperature (LST), Albedo, reference evapotranspiration, soil moisture, Aridity index, satellite-based rainfall etc. also play very significant role in disaster management in agriculture. Such generated agromet products are useful if they were promptly delivered to the end users to reduce disaster management risk for farmer community. Due to this information, farmers can tackle the situations under different extreme weather events and ultimately reduces the impact of bad weather. Efforts have also been made through automated advisory tools to develop a mechanism for generation of agromet advisories along with crop and its stages by using realized data recorded at surface observatories under Network of IMD.

\section{Dissemination of weather forecast, agromet adviso- ries and extension activities}

Dissemination of agromet advisories to the farmers through different multi-channel system of like All India Radio (AIR) and Doordarshan, private TV and radio channels, newspaper and internet, SMS and IVR (Interactive Voice Response Technology) etc. is being made on wider scale. Under PPP mode, Reliance Foundation, Reuter Market Light, IFFCO Kisan Sanchar Limited (IKSL), NOKIAHCL, Handygo, Mahindra Samriddhi, Kisan Sanchar, National Bank for Agricultural and Rural Development (NABARD) are disseminating agromet advisories in SMS and IVR format to the farming community. In addition to that number of AMFUs has started sending agromet advisories through SMS in collaboration with National Informatics Centre (NIC)/Agricultural Technology Management Agency (ATMA)/KVK/NABARD/Internet. Agromet Advisories are also being disseminated in both Regional and English languages through "Kisan SMS", a portal (http://farmer.gov.in/advs/ login.aspx) launched by the Ministry of Agriculture, Government of India. At present 21.69 million farmers are benefitted by this service directly. Weather forecast and advisories under alerts and warnings 
through SMS during extreme weather events are also issued which enable the farmers in planning of farming operations to minimise/ control damage of crops under the adverse weather conditions.

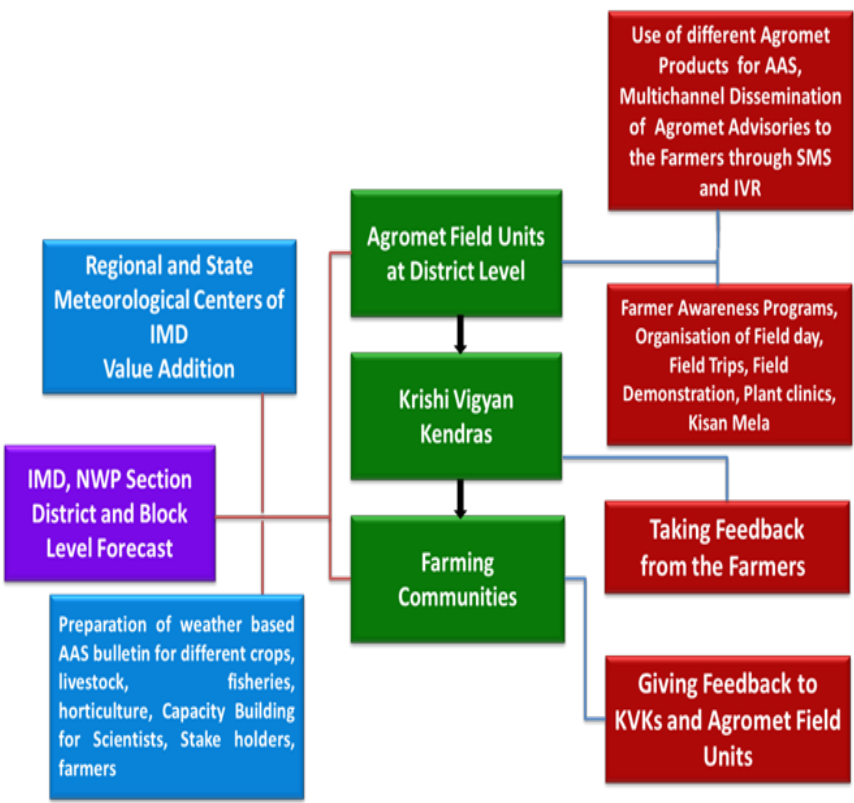

Figure I Overview of Agromet Advisory Services in India.

India Meteorological Department (IMD) in collaboration with Agromet Field Units (AMFUs) disseminates weather forecast and Agromet Advisories to the farming community in the country in both regional and English languages through farmers' portal (http://farmer. gov.in/advs/login.aspx). The services helped the farmers not only in increasing the crop production but also reducing the losses due to inclement weather and other problems. In order to increase the number of farmers in the Kisan Portal, a system of registration through IMD's website has been developed by IMD and National Informatic Centre (NIC), Pune to provide weather based Agromet advisories to more number of farmers through free SMS. To avail this service, farmers are required to register their name and mobile number along with the crops.

\section{Farmers' awareness programmes (FAP)}

Agromet Advisory Services can be strengthened through awareness programmes for the farming communities. Awareness programmes helping are helping the farmers to make more self-reliant in dealing with weather and climate issues that affect agricultural production and also to assist the farmers and further develop their adaptive capacity with improved planning and better management decisions, a participatory, cross-disciplinary approach is being taken to delivering climate and weather information and enhancing the awareness of information user groups. In India, such programmes were organized jointly by the India Meteorological Department (IMD), State agricultural universities, Institutes of the Indian Council of Agricultural Research (ICAR) and Indian Institute of Technology, working with local non-governmental organizations (NGOs) and other stakeholders in different parts of the country. Farmers receive informative brochures; pamphlets outlining weather-based farming guidelines; information on packages and crop practices in the district; leaflets containing information about pests and diseases, severe weather conditions, crops grown under stress conditions and inbuilt contingency plans; and the District Agromet
Bulletin - all in local languages. In order to improve the linkages and develop a local (village) level rain measuring network, five rain gauges made of plastic are distributed to a group of progressive farmers in the programmes. The purpose of distributing the rain gauges is to involve farmers in the observation of weather data and in the preparation of agromet advisories so they can share their observations. Such type of outreach programmes can be Farmer's club meeting, Field Visits by Scientists, Farmers Field Schools etc. In all, 243 farmer awareness programmes were organized at district level by Agromet field units with the funding of IMD. Table 1 depicts Farmer Awareness Programme conducted from 2009 to 2017 in the country.

\section{Generation of agromet products}

Weather information and their departure from normal value at different temporal and spatial scale is useful information for preparation of Agromet Advisories. In view of that IMD is generating the following agromet products as contours on daily, weekly, fortnightly, monthly and Seasonal basis for the parameters temperature (maximum temperature, minimum temperature, diurnal temperature variation), maximum and minimum relative humidity, cloud and wind speed. Also, gridded rainfall data generated daily over India at a grid resolution of $0.25^{\circ} \mathrm{X} 0.25^{\circ}$ of measured rainfall from the large number rain-gauge stations distributed over India is interpolated using IDW interpolation at $0.25^{\circ} \mathrm{X} 0.25^{\circ}$ and spatial district rainfall is generated using GIS software. In addition, soil moisture maps and soil moisture difference are generated using GIS software. Standard Precipitation Index maps and Normalised Difference Vegetation Index (NDVI) maps at State, National and Progress during the week are also prepared. In crop weather calendars, detailed information for each important crop on their dates of sowing dates of commencement and duration of major cultural operations, important periods in their life cycle and their most probable weather requirements is depicted. Figure 2 depicts the different agromet products which are used in Agromet Advisory Bulletins.

\section{Agromet brochure}

IMD has published Agromet Brochure (bi lingual) highlighting the activities, particularly areas of integrated agromet Advisory Services for the benefit of the Indian farmers. Agromet Brochures have been published in 14 different languages viz., Hindi, English, Assamese, Gujarati, Manipuri, Nepali, Punjabi, Tamil, Marathi, Kannada, Telugu, Malayalam and Bengali and circulated for wider publicity.

\section{Economic assessment of the agromet advisory servi- ces}

A study was conducted to assess the economic impact of weather forecast-based advisories 1996, 2009 and 2015 by National Centre for Agricultural Economics and Policy Research (NCAP) in 1996 shows that there is $10-25 \%$ economic benefit obtained by the farmers due to the adoption of agromet advisory services. Also, National Council of Applied Economic Research (NCAER) has estimated the economic benefit of these services in 2009 at Rs. 50,000crores per year is extrapolated to rise to Rs. 211,000 crores if the entire farming community in the country were to apply Agromet information to their agricultural activity. During 2015, again National Council of Applied Economic Research (NCAER) estimated that the economic benefit from the use of weather information as the product of the percentage of farmers receiving information, scenario-wise, times the percentage of farmers benefiting from the information times average profit, crop- 
wise, attributable to weather information times the total national production of crops. Conversion factors, crop-wise, were used to convert farmers' financial profits to economic profits (NCAER, 2015). At present only, 24percent of the farmers are benefitting from the SMS services. The economic profit estimates Rs. 42,000crores. Agromet Services has the potential of generating net economic benefit up to Rs. 3.3lakhcrores on the 22 principal crops when AAS is utilized by all farming households.
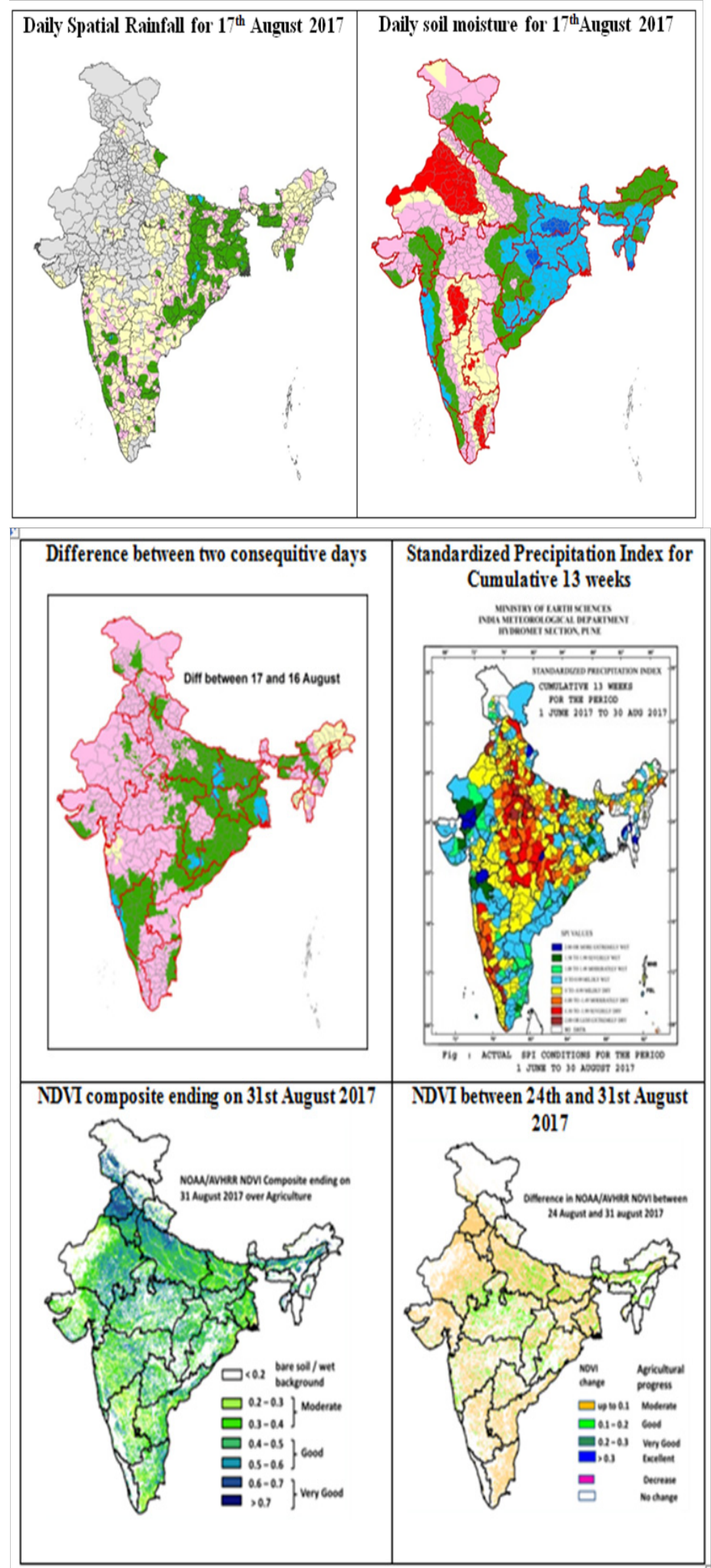

Figure 2 Different agrometproducts for AAS bulletin. 
Table I Farmer Awareness Programme conducted from 2009 to 2017 in the country

\begin{tabular}{|c|c|c|c|c|c|c|c|}
\hline $\begin{array}{l}\text { AMFU } \\
\text { name }\end{array}$ & $\begin{array}{l}\text { Number } \\
\text { of FAP } \\
\text { conducted }\end{array}$ & AMFU name & $\begin{array}{l}\text { Number } \\
\text { of FAP } \\
\text { conducted }\end{array}$ & $\begin{array}{l}\text { AMFU } \\
\text { name }\end{array}$ & $\begin{array}{l}\text { Number } \\
\text { of FAP } \\
\text { conducted }\end{array}$ & AMFU name & $\begin{array}{l}\text { Number } \\
\text { of FAP } \\
\text { conducted }\end{array}$ \\
\hline Anakapalle & 2 & Ranchi & 3 & Keonjhar & I & Bhawanipatna & 2 \\
\hline Anantpur & 3 & Darisai & 1 & Keirei & 2 & G.Udaigiri & I \\
\hline Chintapalle & 2 & Bengaluru & 3 & Ranital & 2 & Kharagpur & 3 \\
\hline Lam & 2 & Bidar & 2 & Similiguda & I & Pundibari & 3 \\
\hline Tirupati & 2 & Vijayapura & 1 & Mahisapat & I & Kakdwip & 2 \\
\hline Hyderbad & 3 & Brahamavar & 3 & Malkangiri & I & Majhian & 4 \\
\hline Jagtiyal & 3 & Dharwad & 1 & Bhatinda & 3 & Port blair & 2 \\
\hline Diphu & 3 & Hiriyur & 2 & Faridkot & I & New Delhi & 3 \\
\hline Gosaigaon & 2 & Naganhalli & I & Gurudaspur & I & & \\
\hline Jorhat & 2 & Neveli & 3 & Ludhiana & 2 & & \\
\hline Karimganj & I & Raichur & 1 & Kandi & I & & \\
\hline Shillongani & 2 & Sirsi & 2 & Bikaner & 2 & & \\
\hline Sonitpur & 2 & Ambalavayal & 2 & Bhartpur & 2 & & \\
\hline Basar & 2 & Kumarakom & 2 & Banswara & 2 & & \\
\hline Pusa & 2 & Pillicode & 2 & Jaipur & 2 & & \\
\hline Sabour & 2 & Thiruvananthpuram & 2 & Jodhpur & I & & \\
\hline Agwanpur & 2 & Vellayani & 2 & Sriganganagar & 2 & & \\
\hline Ambikapur & 3 & Chhindawara & 2 & Udaipur & 2 & & \\
\hline Jagadalpur & 2 & Indore & 2 & Chennai & 3 & & \\
\hline Raipur & 2 & Jabalpur & 2 & Coimbatore & 2 & & \\
\hline Anand & 2 & Jhabua & 2 & Kanniwadi & 2 & & \\
\hline Arnej & 2 & Khargone & 2 & Kovilpatti & 2 & & \\
\hline Bhachau & 2 & Morena & 1 & Aduthurai & 3 & & \\
\hline Dantiwada & I & Sehore & 2 & Namakkal & 2 & & \\
\hline Junagadh & I & Tikamgarh & 1 & Pechiparai & I & & \\
\hline Maktampur & 2 & Akola & 2 & Ooty & 2 & & \\
\hline Navasari & I & Dapoli & 2 & Karaikal & I & & \\
\hline Targhadia & 2 & Igatpuri & 2 & Lembuchera & 2 & & \\
\hline Kaul & 2 & Kolhapur & 2 & Allahabad & 2 & & \\
\hline Hissar & 2 & Mulde & 1 & Baharaich & 2 & & \\
\hline Seobagh & 2 & Parabhani & 2 & Faizabad & I & & \\
\hline Kukumsheri & I & Pune & 1 & Kanpur & 3 & & \\
\hline Palampur & 2 & Rahuri & 1 & Modipuram & 2 & & \\
\hline Solan & 3 & Shindewahi & 2 & Varanasi & 2 & & \\
\hline Jammu & 2 & Lamphelpat & 3 & Pantnagar & I & & \\
\hline Leh & 2 & Barapani & 2 & Ranichauri & 2 & & \\
\hline Rajouri & 2 & Kolasib & 2 & Roorki & 2 & & \\
\hline Srinagar & 2 & Jharanapani & 2 & Kalimpong & 2 & & \\
\hline Dumka & 2 & Bhubaneshwar & 2 & Kalyani & 3 & & \\
\hline
\end{tabular}




\section{Conclusion}

Sustainable development is a set a long-term goal that can only be achieved by a set of management practices. Development of sustainable food production strategies requires a more complete understanding of the limitations of the ecosystem and of the interrelationships between weather and climate, crops, trees and livestock. Proper incorporation of agroclimatic considerations in the development of improved strategies requires a much longer time frame than has been used in the past. Though there is substantial improvement in the weather services to the farmers but yet a substantial body of research also shows that the availability of information is not sufficient for unreached and poor farmers in the villages to benefit. These farmers need both weather and climate services for better crop production. Agromet Advisory services for agriculture that is, the provision of accurate and locally-appropriate climate and weather information play a vital building block for increasing the resilience of communities to climate change, diseases, and disasters. A new initiative, the Global Framework for Climate Services (GFCS), is working to enhance the capability of many countries to provide these services, so that they can adequately plan for the future. Through India Meteorology Department (IMD)'s national Agro-meteorological Advisory Service (AAS) program, Gramin Krishi Mausam Seva, farmers across the country have been receiving, weather-based, crop-focused agrometeorological advisories at district level for a number of years. Now IMD has planned to strengthen the service in terms of observation, seamless weather forecast, manpower, real time information flow, research and development (R\&D), dissemination etc. This present system of delivering the services at district level is underway to extend up to sub-district/ block level with dissemination up to village level to meet the end user's requirements in both the irrigated and rain fed systems. Establishment of 660 District Agrometeorological Units (DAMUs) in each district of India at Krishi Vigyan Kendra (KVK) is under pipeline which includes 130 existing AMFUs till 2019 with the objective of preparing customized advisory at sub district/block level with medium range block level weather forecast. So that small and marginal farmers will be benefitted by these services.

\section{Acknowledgements}

The authors are thankful to the officers and staff members of the Agricultural Meteorology Division, India Meteorological Department, Pune, India for their help in the preparation of the paper.

\section{Conflict of interest}

The authors declare that there is no conflict of interests regarding the publication of this paper.

\section{References}

1. Sivakumara MVK, Gommesb R, Baierc W. Agrometeorology and sustainable agriculture. Agricultural and Forest Meteorology. 2000;103(1-2):11-26.

2. Stigter CJ. From basic agrometeorological science to agrometeorological services and information for agricultural decision makers: a simple conceptual and diagnostic framework. A Guest Editorial. Agric For Meteorol. 2007;142:91-95.

3. Chattopadhyay N, Lal B. Agrometeorological Risk and Coping Strategies-Perspective from Indian Subcontinent: Managing Weather and Climate Risks in Agriculture. Springer Publication, New York, UK; 2007. p. 83-97.

4. Chattopadhyay N, Rathore LS. Extreme Events: Weather service for Indian Agriculture. Geography and You. 2013;13(79):12-16.

5. Rathore LS, Chattopadhyay N, Singh KK. Reaching farming communities in India through Farmer Awareness Programmes. Climate Exchange, World Meteorological Organisation (WMO), Tudor Rose publication, United Kingdom; 2013. p. 20-23. 